\title{
MARCIN TELICKI
}

Wydział Filologii Polskiej i Klasycznej

Uniwersytetu im. Adama Mickiewicza w Poznaniu

\section{ECO I BARAŃCZAK - DWA SPOSOBY MÓWIENIA O KULTURZE POPULARNEJ W EUROPIE ŚRODKOWEJ}

Zajmę się tu komparatystyką szczególnego rodzaju. Staną obok siebie Umberto Eco i Stanisław Barańczak, włoski i polski literaturoznawca, obydwaj bardziej znani szerszej publiczności z tego, że byli pisarzami. Badacze zainteresowani wąską specjalistyczną dziedziną wiedzy (teorią literatury, semiotyką i historią idei), a równocześnie rozumiejący kulturę masową i uczestniczący w niej. Krytycznie, ale z wyraźną i jawnie okazywaną przyjemnością. Miłośnicy literackich zabaw i wnikliwi obserwatorzy rzeczywistości. Obydwaj będący w swojej epoce pionierami, ale mający też bratnie krytyczne dusze, na co wskazuje choćby paralela między Barańczakiem a Barthesem:

Przy wszystkich różnicach zestawienie tomu francuskiego krytyka [Mitologii Rolanda Barthesa - przyp. M.T.] i Barańczaka jest zasadne, gdyż obaj uprawiają podobny gatunek, który zasługuje na miano felietonu analitycznego. Obu zajmują różnorodne przejawy kultury masowej, rozpatrywane $\mathrm{w}$ nieobojętnym kontekście społecznym. (...) Obaj posługują się poszerzonym pojęciem tekstu, obaj też korzystają z narzędzi semiologicznych. U obu wreszcie da się wyczytać rodzaj programu społecznego: ich interpretacje fenomenów kultury masowej są aktami demistyfikacji1.

Pola i procesy „demistyfikacji” kultury masowej dokonywane przez Eco i Barańczaka będą mnie interesowały w dwóch aspektach: po pierwsze - jako krytyczne rozpoznania nowatorskie w swoim czasie (lata 60. i 70. XX wieku), po drugie - jako wciąż aktualne tezy w dyskursie teorii popkultury.

${ }^{1}$ A. Poprawa, Postowie, w: S. Barańczak, Odbiorca ubezwlasnowolniony. Teksty o kulturze masowej i popularnej, wyb., oprac. i posł. A. Poprawa, Wrocław 2017, s. 498. Podobną paralelę przeprowadza Barbara Klinger między Barthesem a Eco w odniesieniu do intertekstualności: „Choć Barthes i Eco różnią się znacznie w swoich perspektywach teoretycznych (poststrukturalizm Barthesa, neopeircowska perspektywa Eco), oboje odrzucają ideę samoregulującego się tekstu, podkreślając kluczową rolę czynników intertekstualnych w semantycznej aktualizacji tekstu. Jako takie, ich rozumienie intertekstualności i jej przejawów w dygresyjnych sposobach czytania stanowi prowokacyjny sposób otwarcia tekstu na znaczące działanie form heterogenicznych". B. Klinger, Digressions at the Cinema. Commodification and Reception in Mass Culture, w: Modernity and Mass Culture, red. J. Naremore, P. Brantlinger, Bloomington and Indianapolis 1991, s. 120. 


\section{Wypracowywanie znaczeń}

Jak wiemy, krytycy kultury popularnej są (byli) wyznawcami dualistycznego podziału aksjologicznego wyrażającego się w określeniach nacechowanych wartościująco (wysokieniskie, elitarne-popularne, artyzm-kicz itd.). Podejście takie wymagało pokazania popkultury w kontraście wobec modelu obowiązującego. Eco na arenie międzynarodowej, a Barańczak w obrębie polskiej humanistyki dokonali znaczącego zwrotu polegającego na demokratyzacji procesu czytania kultury. To, co masowe/popularne przestało być domeną kontrkultury, zaczęło natomiast być postrzegane jako jeden spośród głosów - odmienny, ale równoprawny (Eco pisał, że „gdzie troje ludzi rozmawia o kulturze, przynajmniej jeden z nich rozumie ją inaczej niż pozostali" ${ }^{2}$ ).

Stawiam tezę, że autorzy Supermana w kulturze masowej i Odbiorcy ubezwtasnowolnionego wybierają trzecią drogę między elitaryzmem a populizmem kulturowym. Dominic Strinati pisał o nich w podsumowaniu swojego Wprowadzenia do kultury popularnej, zauważając, że pierwsze podejście cechuje się biernością i naiwnością publiczności, która poddaje się medialnej manipulacji, natomiast drugie zakłada świadomość odbiorców i zastosowanie przez nich mechanizmów oporu:

Podczas gdy elitaryzm traktował publiczność z góry, nazywając ją naiwną, populizm czyni podobnie, ale nazywa publiczność wywrotową. Ale i populizm ciągle zdaje się mówić „w imieniu”, a nie „do" publiczności. Jeśli elitarystyczne ujęcie publiczności jest błędne, jest takim również ujęcie populistyczne i to z tych samych powodów. Oba są nieuprawnionymi karykaturami bez należytego empirycznego i historycznego docenienia społecznej i kulturowej natury publiczności ${ }^{3}$.

Barańczakowi, jak się zdaje, nieco bliżej jest do postawy elitarystycznej niż Eco, ale nie sądzę, by popadał w skrajność wskazywaną przez Strinatiego ${ }^{4}$. Jednemu i drugiemu pomaga szczególny rodzaj pragmatyzmu, pozwalającego być „obserwatorem uczestniczącym”, czy - jak pisze Teresa Walas - „narzędziem uświadomionej homogenizacji”, które gdy trzeba, służy semiologicznej partyzantce ${ }^{5}$.

Jeden z wniosków z dokonanego powyżej przeglądu można by sformułować następująco: u obydwu badaczy następuje przesunięcie od pragmatycznego „my ekskluzywnego" (my, ale nie ty - rozdzielającego wspólnotę uczestników kultury popularnej i wspólnotę uniwersytetu) do „my inkluzywnego” (jesteśmy razem w nadawczo-odbiorczej wspólnocie

${ }^{2}$ U. Eco, Apocalipse postponed, red. R. Lumley, Londyn 1994, s. 115, cyt. za: R. Capozzi, Eco's Prophetic Vision of Mass Culture, „McLuhan Studies”, http://projects.chass.utoronto.ca/mcluhan-studies/v1_iss1/1_1art10. htm (data dostępu: 17.07.2019 [tłum. własne]).

3 D. Strinati, Wprowadzenie do kultury popularnej, przeł. W.J. Burszta, Poznań 1998, s. 204.

${ }^{4}$ Inaczej uważa Teresa Walas, która komentując wznowienie Odbiorcy ubezwłasnowolnionego, pisała: „Najistotniejszy był dla niego [Barańczaka - przyp. M.T.] fakt, że produkty, które poddawał porywającej częstokroć analizie (...), są zazwyczaj pokarmem zatrutym, projektują bowiem, a w konsekwencji wytwarzają, osobowość bierną, reaktywną, umysł niezdolny do krytycznej refleksji, paraliżowany przez niekontrolowane emocje, czyli odbiorcę ubezwłasnowolnionego”. T. Walas, Odsłony popkultury: od Barańczaka do Masłowskiej, „Nowa Dekada Krakowska" 2018, nr 1, s. 107.

5 Ibidem, s. 108. Walas odwołuje się tu naturalnie do pojęcia wyjętego z semiologicznego słownika Eco. Artykuł pod tytułem Partyzantka semiologiczna (na język polski przełożony przez Joannę Ugniewską) jest częścią zbioru Semiologia życia codziennego, Warszawa 1996, s. 157-167. 
użytkowników kultury, bez względu na to, jak różnie oceniamy jej poziom i bez względu na to, jakie mamy kompetencje do formułowania takich ocen).

\section{Wspólnoty odbiorcze}

Z wniosku wieńczącego część pierwszą wynika teza kolejna: i Barańczak, i Eco decydują się na włączenie głosu uniwersytetu do debaty nad kulturą popularną, ponieważ uniwersytet powinien mieć związek z życiem codziennym (choć na poziomie głębszym niż chcieliby kulturowi „populiści”). John Fiske proponuje, by postrzegać tę relację między innymi poprzez kategorię adekwatności. Polega ona na poszukiwaniu punktów stycznych między „zasobem kulturowym” a doświadczeniem życia codziennego.

Ze względu na zmieniające się sojusze społeczne - przekonuje autor książki Zrozumieć kulture popularna - nie istnieje jasno sprecyzowany sposób doświadczania i przeżywania codzienności, dlatego też takich punktów styczności musi być wiele. Ponadto każdy z nich powinna cechować przejściowość oraz otwartość na społeczne, a nie tekstualne uwarunkowania ${ }^{6}$.

Z dwoma postulatami omawiani badacze-pisarze byliby, jak sądzę, skłonni się zgodzić. Nieokreśloność życia codziennego i zaskakujące nieraz punkty styczne sztuki i doświadczenia były wręcz motorem interpretacji (bo skoro interpretować można wszystko, to ,niezwykłość" materiału może zwiększać potencjał tekstu krytycznego) - to najpierw. Po wtóre zaś nieobca była ich analizom otwartość na uwarunkowania społeczne, a bez uważnej socjologicznej interpretacji obniżyłaby się merytoryczna wartość ich rozważań, ale także niewątpliwy wdzięk (choć słowo to nie posiada wartości naukowego kwalifikatora, określa ten rodzaj Barthesowskiej ,przyjemności tekstu”, która potrafi zjednać zarówno odbiorców profesjonalnych, jak i nieprofesjonalnych ${ }^{7}$ ).

Trzeci postulat Fiskego wymaga osobnego omówienia. Co badacz chce przekazać, gdy mówi, że adekwatność zasadza się na uwarunkowaniach społecznych, a nie tekstualnych? Otóż w jego optyce „tekstualność” wiąże się z tradycyjnie rozumianą estetyką, której trwałe kategorie nie pozwalają na odpowiednią ocenę wytworów społeczeństwa pozbawionego dawno wypracowanych punktów styku życia i sztuki. Jak pisze Fiske ,natura sojuszy społecznych jest zmienna", a przeciwstawia się jej ciągle estetykę jako system dyscyplinujący, który wymaga formalnego procesu kształcenia ${ }^{8}$. Tymczasem Eco i Barańczak fundują swo-

${ }^{6}$ J. Fiske, Zrozumieć kulturę popularna, przeł. K. Sawicka, Kraków 2010, s. 133.

7 „Kompromisowe” nastawienie Eco można opisać, odwołując się do słów znawcy jego dzieła - Petera Bondanelli: „Wyjaśnienie faktu, dlaczego czytelnik zwykle łaknie (...) wysoce redundantnych opowieści, łączy teoretycznoliterackie zainteresowania Eco z pragnieniem zreformowania społeczeństwa. Według niego współczesne społeczeństwo przemysłowe bombarduje jednostkę «nieprzerwanym strumieniem informacji, stanowiących dla niej wstrząs i zakładających ciągłą przemianę wrażliwości, przyswajanie psychologicznych przekonań i przestrajanie umysłowego nastawienia», co powoduje, że nawet najbardziej wykształceni intelektualiści zwracają się ku redundantnym opowieściom, traktując je jak «zaproszenie do odpoczynku, jedyną okazję prawdziwego odprężenia, jaką proponuje się odbiorcy», gdy tymczasem kultura wysoka lub wysublimowana sztuka «proponują jedynie zmieniające się schematy, gramatykę, która wciąż obala swą poprzedniczkę, oraz ciągle przekształcające się kody»". P. Bondanella, Umberto Eco. Semiotyka, literatura, kultura masowa, przeł. M.P. Markowski, Warszawa 1997, s. 61-62.

8 Ibidem, s. 134. 
je badania na wiedzy z historii idei oraz na szeroko rozumianych kategoriach tekstowych - jak przystało na uczonych, którzy wyrośli na tradycji strukturalno-semiotycznej i nawet, gdy poza nią wykraczają, pozostają pod jej przemożnym wpływem. Próbę takiego myślenia odnajdujemy choćby w Czytelniku ubezwłasnowolnionym: „,[m]ożliwość takich czy innych skutków społecznych odbioru widzi (...) badacz już w samym tekście - analizując wewnątrztekstowe czynniki, które tak czy inaczej ów odbiór programują" dzenia Fiskego „utekstowione” doświadczenie byłoby niepełne i nieadekwatne wobec oczekiwań współczesnego społeczeństwa. Moim zdaniem jednak porzucenie takiego sposobu czytania może ciążyć ku populizmowi kulturowemu, gdyż zbyt łatwo przesuwa się badanie analogii tekstowych do dziedziny regresywnych i obcych większości społeczeństwa praktyk akademickich ${ }^{10}$.

Zarówno socjologiczne podejścia Fiskego, jak i (post)tekstualny, wywiedziony z semiotyki sposób lektury uprawiany w różnych wariantach przez Barańczaka i Eco znajdują jednak punkty styczne w twierdzeniu, że kultura popularna jest określoną wersją wspólnotowości.

Na marginesie wspomnijmy, że kultura popularna była różna na Zachodzie i w bloku komunistycznym. Pozorna oczywistość tego zdania mogłaby mieć jednak ciągi dalsze w postaci pytań i dopowiedzeń. Jakie są zależności między ustrojem państwowym a modelem jego kultury („Barańczak doskonale zdawał sobie sprawę z paradoksalnej natury przedmiotu swoich badań, czyli z faktu, że kultura masowa, z którą ma do czynienia, powstaje w państwie realnego socjalizmu, posługującym się dyscyplinującymi narzędziami polityki kulturalnej, i sygnalizował wewnętrzną sprzeczność między rozrywką, jakiej pożądały masy, a propagandą, na której zależało władzy"11)? W jaki sposób dokonuje się recepcji pewnych dominujących modeli kultury masowej (amerykanizacja postrzegana przez krytyka polskiego i włoskiego)? I wreszcie: czy wspólnotowość tej kultury sama nie została nadmiernie zmitologizowana?

Szczególnie ważną inspiracją dla badań są konteksty pragmatyczne (z wiodącą rolą Peirce'a). Opisywanych badaczy cechuje też nastawienie dydaktyczne, nie tylko w wąskim zakresie nauczania studentów - a obydwaj byli cenionymi nauczycielami akademickimi ale przede wszystkim $\mathrm{w}$ znaczeniu wychowywania społeczeństwa zagubionego w coraz bardziej skomplikowanym otoczeniu semiotycznym. W jednej z ostatnich swoich prac Eco próbuje oświetlić wyzwania, które przynosi najbardziej wpływowe dziś narzędzie społecznościowe, jakim jest Internet, i ukazać zadania semiotyka:

9 S. Barańczak, Odbiorca ubezwłasnowolniony, op.cit., s. 226.

${ }_{10}$ Problem ten stawia m.in. Carolyn Jan Swearingen, rozważając zależności między „starymi” a „,nowymi” wspólnotami interpretacyjnymi: „Nowe wspólnoty znaczeniowe są być może wspólnotami podejrzliwymi wobec podzielanego znaczenia, wspólnej wiedzy, a także tekstów, które niegdyś określano jako literaturę. Czyżby modernistyczna metoda lektury poszukującej jedynie znaczenia, prawdy naukowej bądź referencyjnej, znalazła się już - bez możliwości ucieczki - poza modelem wspólnoty? Czy indywidualistyczne modele wiedzy i lektury są anty- lub niewspólnotowe?". W całym artykule autorka poszukuje argumentów na rzecz tezy, że współczesne praktyki interpretacyjne nie zrywają ze sposobami czytania i pisania obecnymi od czasów starożytnych, ale stanowią ciąg zjawisk ewoluujących. C.J. Swearingen, Czym jest tekst? Kim jest czytelnik? Medytacja o meandrach znaczenia, w: Literackie doświadczenie nowoczesności. Antologia artykułów z „New Literary History”, pod red. G. Grochowskiego i R. Nycza, przeł. O. Mastela, Warszawa 2017, s. 131.

11 T. Walas, op. cit. 
Po pierwsze, (...) w semiozycznej wirtualności Sieci (w istocie tworu bardzo dekonstruktywnego) ryzykujemy zagubienie idei celu i działania. Po drugie, (...) jednym z obowiązków przyszłej semiotyki będzie prawdopodobnie uczenie ludzi nie tylko jak używać znaków w surfowaniu po nieskończonym oceanie semiozy, ale także jak wrócić, nie raz na zawsze, ale zawsze na każdym etapie semiozycznych poszukiwań, do Przedmiotu Dynamicznego ${ }^{12}$.

Zatem, żebyśmy nie byli wspólnotą urojoną, ale rzeczywistą, musimy uporządkować znaki i - choćby w ograniczonym zakresie - zrozumieć ich mitotwórczą moc. Co ważne, odkrycie organizacji znaków nie ma nas prowadzić do powstania abstrakcyjnej klasyfikacji, ale na ile to możliwe do powrotu do samej rzeczy. Dziś rzeczy (zjawiska, wydarzenia) bywają przez znaki zasłonięte tak szczelnie, że nie widać już ich pierwotnego kształtu. Dlatego właśnie potrzebna jest nowa edukacja semiotyczna.

\section{Ukryta retoryka}

Od ostatniej uwagi o wspólnotowości i potrzebie wychowania do rozumienia systemów znakowych przejdźmy do punktu ostatniego, który moim zdaniem najpełniej charakteryzuje projekty analizy kultury popularnej omawianych autorów. Otóż badania nad kulturą masową można by uznać za część rozwijających się od kilku dekad everyday life studies, dla których semiotycznym (pragmatycznym) punktem wyjścia jest odkrywanie i problematyzowanie mechanizmów świadomie zakrytych w procesie nadawania komunikatu lub powstających samorzutnie:

(...) za jeden z dopuszczalnych synonimów codzienności przyjął Eco oczywistość: codzienne, a więc oczywiste (bądź na odwrót) są te przedmioty, te zjawiska. które - z racji pewnej ideologii naukowej - nie były dotąd problematyzowane, tematyzowane w dyskursie wykraczającym poza mowę potoczną. Fenomeny odrzucone zdają się stanowić zręby tego, co określa się mianem „codzienności”. Zadanie, jakie postawił przed sobą autor, polega na odkryciu w tych wszystkich faktach ładunku nieprzeczuwanej dotychczas „odmienności”; aby z oczywistego uczynić problematyczne, a spod warstwy uspokajającej zwyczajności wyłuskać element obcości ${ }^{13}$.

Niemal to samo krytyczne nastawienie odnajdziemy w wypowiedzi Barańczaka:

(...) Współczesne badania nad perswazją w kulturze masowej dotyczą zdecydowanie najczęściej tych rodzajów tekstów, w których obecność perswazji jest poniekąd oczywista i naturalna - gdyż ich zasadniczą funkcją społeczną jest właśnie nakłanianie odbiorców do tych czy owych zachowań lub zjednywanie ich dla tych czy owych poglądów. Myślę, rzecz prosta, o reklamie i propagandzie oraz im właściwych środkach perswazyjnych (...). Znacznie rzadziej dostrzegany jest fakt, że perswazja bywa nawet i skuteczniejsza, gdy zakamuflowana jest w tekstach niemających z pozoru nic wspólnego z ,profesjonalnym” nakłanianiem, w tekstach, w których z zasady powinna dominować funkcja estetyczna, poznawcza, emotywna... Również i tutaj dostrzec można przejawianie się wyrazistych, choć utajonych „kodów retorycznych”, typowych chwytów perswazyjnych wchodzących w skład retorycznego repertuaru kultury masowej ${ }^{14}$.

12 U. Eco, Przyszłość semiotyki, w: Ecowskie inspiracje. Semiotyka w komunikacji i kulturze, pod red. A. Gałkowskiego i K. Pietrych, tłum. M. Kopytowska, Łódź 2017, s. 20.

${ }^{13}$ W. Kędzierzawski, ,Semiologia życia codziennego” Umberta Eco - próba interpretacji, w: Wokół Eco, pod red. Z. Żmigrodzkiego przy współudziale D. Pietruch-Reizes, Katowice 2000, s. 28.

14 S. Barańczak, Stowo - perswazja - kultura masowa, w tegoż: Odbiorca ubezwłasnowolniony, op. cit., s. 230. 
Te dwie długie wypowiedzi ukazują, jakie sposoby działania kultury masowej uważa się za dominujące. Przede wszystkim kultura popularna nie jest transparentna - jeśli przeciętny odbiorca ma ją konsumować, to nie może być w pełni świadomy, że jego uwagę kieruje się ku określonemu produktowi czy ideologii. Z drugiej jednak strony, kultura od zawsze operowała tym rodzajem ukrywania mechanizmów swojego działania, których rozumienie było dane tylko części odbiorców ${ }^{15}$. Zadanie interpretatora wyznaczone zostało zatem dość wyraźnie: jest to praca dekodowania, odsłaniania tego, co ukryte ${ }^{16}$. Nie ma przy tym jednego narzędzia i jednego kodu (jak tego chciała część strukturalistów sprowadzających pojedyncze elementy do funkcji całości), są poszczególne teksty. Znamienna była polemika Rorty’ego i Eco dotycząca tego zagadnienia. Gdy Rorty stwierdził, że „,zabawa z tekstem" różnicuje się u Eco w zależności od rejestru, który wybiera (narracja teoretyczna versus narracja powieściowa), ten odpowiedział, że oczekiwanie spójności systemu nie jest charakterystyczne dla pragmatyki i wydaje się sprzeczne z założeniami „słabej” interpretacji. Jeden i drugi uznawali jednak, że nie można zejść poniżej pewnego stopnia struktury logicznej, gdyż wówczas tekst (dzieło, zbiór dzieł) stanie się niekomunikatywny ${ }^{17}$.

Świat wedle Umberta Eco jest tajemniczy nie dlatego, że jest niejasny i niezrozumiały, lecz dlatego, że można go zrozumieć jedynie dociekając tego, co zasłania kurtyna pozornej zrozumiałości. (...) W odróżnieniu od jasnego i dążącego wszelkimi środkami do wyrugowania tajemnicy świata informacji i przekazu tzw. „faktów”, myśliciel widzi swoją rolę w obronie tego, co przesłonięte jest mrokiem i co niczego nam nie podaje w gotowej postaci, lecz jedynie daje nam do myślenia ${ }^{18}$.

${ }^{15} \mathrm{~W}$ jednym z wywiadów na pytanie Tadeusza Sobolewskiego „Czy takiej masowej perswazji nie znały w innej formie - poprzednie epoki?” Stanisław Barańczak odpowiada: „Oczywiście, starożytni retorzy też manipulowali świadomością swoich słuchaczy i robili to po mistrzowsku. Ale perswazyjne działanie słowa jest dzięki tej długiej tradycji - sprawą stosunkowo dobrze znaną". W dalszej części zaś przekonuje, że język filmu i reklamy czyni sprawę bardziej złożoną: „Widać tu pewien ogólniejszy mechanizm: producent czy dysponent tekstu stara się odwoływać do pewnych powszechnych systemów wartości, do ogólnie akceptowanych przekonań czy fascynacji. Nawiązuje w ten sposób porozumienie $\mathrm{z}$ widzem (...) i dzięki temu może - choćby to było najzupełniej nielogiczne - przemycić pewien korzystny dla siebie wniosek (...)”. T. Sobolewski, Atrakcje i niebezpieczeństwa. Rozmowa ze Stanisławem Barańczakiem, „Film” 1975, nr 13, przedruk w: S. Barańczak, Odbiorca ubezwlasnowolniony, op. cit., s. 427-428.

${ }^{16} \mathrm{~W}$ niektórych tekstach Umberto Eco łączy perswazję z obrazem: „Kiedy mamy do czynienia z (...) nowymi sytuacjami o charakterze mitotwórczym, wydaje nam się, że powinniśmy postępować w sposób odznaczający się dwiema cechami: $\mathrm{z}$ jednej strony powinno to być badanie celów, których ucieleśnieniem jest obraz, tego, co następuje po kontakcie $\mathrm{z}$ obrazem; $\mathrm{z}$ drugiej strony powinien to być proces demistyfikacji, polegający na odkryciu tego, co kryje się za obrazem, a więc nie tylko nieświadomych potrzeb, które go wypromowały, lecz również świadomych wymagań paternalistycznej dydaktyki, ukrytej perswazji kierującej się określonymi celami ekonomicznymi”. U. Eco, Apokaliptycy i dostosowani. Komunikacja masowa a teorie kultury masowej, przeł. P. Salwa, Warszawa 2010, s. 319-320.

17 Tezy powtarzam za: A. Muchowicz, Perspektywy metadyskursu dialektyki otwartej. Wokót Umberta Eco „logiki kultury”, Bydgoszcz 2009, s. 111-112.

${ }_{18}$ T. Sławek, Filozof w Bibliotece Babel. Refleksje na okoliczność przyznania Profesorowi Umbertowi Eco honorowego doktoratu honoris causa Uniwersytetu Łódzkiego, w: Potęga intelektu. Umberto Eco: recepcja i reminiscencje w Polsce. Ksiega dedykowana Profesorowi Umbertowi Eco, doktorowi honoris causa Uniwersytetu Łódzkiego, pod red. A. Gałkowskiego, Łódź 2015, s. 99. 
Semiotyk udowadania więc, że problemem współczesnego świata jest nadmierna zrozumiałość. Z niej rodzi się przeciążenie informacyjne, to ona jest przyczyną nieporozumień w definiowaniu kultury popularnej, w niej swój początek ma kicz, w niej możemy dopatrzeć się źródeł mentalności tłumu (,wszyscy tak robią”) ${ }^{19}$. Maszyny medialne i ekonomiczne nie pozwalają na pokazywanie pęknięć w obrębie swojego działania, prezentując je jako jednolite i wewnętrznie niesprzeczne. Do zdemaskowania „ukrytej retoryki” potrzebny jest zaangażowany użytkownik, mający kompetencje kulturowe i potrafiący odnaleźć drogę między elitarystycznym odłączeniem (od uniwersyteckiej „wysokiej teorii” po popularne teorie spiskowe) a populistyczną inkorporacją wszelkich przejawów ludzkiej twórczości.

Autorzy Nieobecnej struktury i Czytelnika ubezwłasnowolnionego podążyli, moim zdaniem, właśnie tą trzecią drogą, wyznaczając kierunek badaniom kultury popularnej. O ich pionierskiej działalności nie zawsze się dziś pamięta ${ }^{20}$, na pierwsze miejsce zdecydowanie wysuwa się ich twórczość poetycka i prozatorska (choć, jak widzieliśmy wcześniej, nie powinno się ich sztucznie rozdzielaćéc). Czy teoretyczne rozpoznania Eco i Barańczaka zostaną podjęte i będą twórczo rozwijane przez kolejne pokolenia? Czas pokaże.

\section{Bibliografia}

Barańczak S., Odbiorca ubezwłasnowolniony. Teksty o kulturze masowej i popularnej, wyb., oprac. i posł. A. Poprawa, Wrocław 2017.

Bondanella P., Umberto Eco. Semiotyka, literatura, kultura masowa, przeł. M.P. Markowski, Warszawa 1997.

Capozzi R., Eco's Prophetic Vision of Mass Culture, „McLuhan Studies”, http://projects.chass.utoronto.ca/mcluhan-studies/v1_iss1/1_1art10.htm (dostęp: 17.07.2019).

Eco U, Apokaliptycy i dostosowani. Komunikacja masowa a teorie kultury masowej, przeł. P. Salwa, Warszawa 2010.

Eco U., Apocalipse postponed, red. R. Lumley, Londyn 1994.

Eco U., Partyzantka semiologiczna, przeł. J. Ugniewska, w: Semiologia życia codziennego, Warszawa 1996.

19 Repetycje kultury masowej podsumowuje Eco bardzo celnie: „Uspokojenie, które w literaturze masowej jest rezultatem pocieszenia polegającego na powtarzaniu oczekiwanych rozwiązań, z punktu widzenia ideologii równoznaczne jest z reformą zmieniającą coś niecoś po to, aby wszystko pozostało niezmienione. A zatem chodzi o formę ładu będącego skutkiem jednorodnych powtórzeń i trwałości uznanych powszechnie znaczeń. Ideologia i struktura narracyjna spotykają się i łączą ze sobą w sposób wręcz doskonały". U. Eco, Superman w literaturze masowej. Powieś́ popularna: między retoryka a ideologia, przeł. J. Ugniewska, Warszawa 1996, s. 87.

${ }^{20}$ Znamienny komentarz umieszcza Adam Poprawa w posłowiu do książki Barańczaka: „Dzisiaj, kiedy można przejść drogę naukową od licencjata do profesora emerytowanego, zajmując się wyłącznie kulturą popularną - łatwo zapoznać, jak wiele humanistyka polska zawdzięcza Barańczakowi”. A. Poprawa, op.cit., s. $493-494$.

${ }^{21}$ „Fikcjonalne utwory Eco zestawione z wieloma esejami i książkami poświęconymi przez niego definiowaniu kultury (zarówno popularnej, jak i wysokiej) pokazują, że jego rozumienie kultury ewoluujące od nowoczesnego spektrum kiczu do postmodernistycznego celebrowania intertekstualności podąża za sugestią intelektualnego rozwoju, który wynika z początkowych intuicji Eco dotyczących arbitralności i względnej natury różnych form kulturowych. Dzieła zebrane Eco jawią się jako ogromny wkład w definicję kultury postmodernistycznej, ponieważ dają wymowne świadectwo możliwości połączenia niskich i wysokich form ekspresji we współczesnym świecie". New Essays on Umberto Eco, red. P. Bondanella, Nowy Jork 2009, s. 15. Tłumaczenie własne - M.T. 
Eco U., Przyszłość semiotyki, w: Ecowskie inspiracje. Semiotyka w komunikacji i kulturze, pod red. A. Gałkowskiego i K. Pietrych, tłum. M. Kopytowska, Łódź 2017.

Eco U., Superman w literaturze masowej. Powieść popularna: między retoryka a ideologia, przeł. J. Ugniewska, Warszawa 1996.

Fiske J., Zrozumieć kulturę popularna, przeł. K. Sawicka, Kraków 2010.

Kędzierzawski W., ,Semiologia życia codziennego” Umberta Eco - próba interpretacji, w: Wokót Eco, pod red. Z. Żmigrodzkiego przy współudziale D. Pietruch-Reizes, Katowice 2000.

Klinger B., Digressions at the Cinema. Commodification and Reception in Mass Culture, w: Modernity and Mass Culture, red. J. Naremore, P. Brantlinger, Bloomington and Indianapolis 1991.

Muchowicz A., Perspektywy metadyskursu dialektyki otwartej. Wokót Umberta Eco „, logiki kultury”, Bydgoszcz 2009.

New Essays on Umberto Eco, red. P. Bondanella, Nowy Jork 2009.

Poprawa A., Posłowie, w: S. Barańczak, Odbiorca ubezwłasnowolniony. Teksty o kulturze masowej i popularnej, wyb., oprac. i posł. A. Poprawa, Wrocław 2017.

Sławek T., Filozof w Bibliotece Babel. Refleksje na okoliczność przyznania Profesorowi Umbertowi Eco honorowego doktoratu honoris causa Uniwersytetu Łódzkiego, w: Potęga intelektu. Umberto Eco: recepcja i reminiscencje w Polsce. Księga dedykowana Profesorowi Umbertowi Eco, doktorowi honoris causa Uniwersytetu Łódzkiego, pod red. A. Gałkowskiego, Łódź 2015.

Sobolewski T., Atrakcje i niebezpieczeństwa. Rozmowa ze Stanisławem Barańczakiem, „Film” 1975, nr 13, przedruk w: S. Barańczak, Odbiorca ubezwlasnowolniony. Teksty o kulturze masowej i popularnej, wyb., oprac. i posł. A. Poprawa, Wrocław 2017.

Strinati D., Wprowadzenie do kultury popularnej, przeł. W.J. Burszta, Poznań 1998.

Swearingen C.J., Czym jest tekst? Kim jest czytelnik? Medytacja o meandrach znaczenia, w: Literackie doświadczenie nowoczesności. Antologia artykułów z „New Literary History”, pod red. G. Grochowskiego i R. Nycza, przeł. O. Mastela, Warszawa 2017.

Walas T., Odstony popkultury: od Barańczaka do Masłowskiej, „Nowa Dekada Krakowska” 2018, nr 1.

\section{MARCIN TELICKI}

\section{Eco and Barańczak: two ways of speaking about popular culture in Central Europe}

\section{Summary}

The author's academic goal is to check the effects of a parallel drawn between culture theoreticians known to the audience as writers. Both Umberto Eco (Apocalypse Postponed, Superman in Mass Culture) and Stanisław Barańczak (Incapacitated Reader) presented in their writing measured, non-elitist views of figments of collective imagination by referring to structuralism and semiotics - professional tools applied in literary criticism and cultural studies. The article offers a diagnosis of the position of the texts in question at the time of their origin. It also shows the reception of the ideas of the Polish and Italian literary critics and their creative continuations. A closer look at the specific theories related to terminology (mass culture - elitist culture), the role of the media and concealed rhetoric mechanisms leads to questions about the perspective of research into culture in the course of dynamic changes.

Keywords: Umberto Eco, Stanisław Barańczak, popular culture, semiotics, rhetoric, culture criticism. 